\title{
GAIA Level 1 Uterine Rupture
}

National Cancer Institute

\section{Source}

National Cancer Institute. GAIA Level 1 Uterine Rupture. NCI Thesaurus. Code C128752.

GAIA Level 1 Uterine Rupture is the complete disruption of the uterus, at the time of laparotomy, in the context of vaginal or intra-abdominal bleeding. 